\section{1 of 2 quality improvement interventions for depression in managed care was more effective but more costly than usual care}

\author{
Schoenbaum M, Unützer J, Sherbourne C, et al. Cost-effectiveness of practice-initiated quality improvement for depression. \\ Results of a randomized controlled trial. JAMA 2001 Sep 19;286:1325-30. \\ QUESTION: In patients with depression, are either of 2 quality improvement (QI) \\ interventions for improving the treatment of depression in managed care more cost \\ effective than usual care?
}

Sources of funding: Agency for Healthcare Research and Quality; National Institute of Mental Health;John D and Catherine $T$ MacArthur

Foundation.

For correspondence: $\mathrm{Dr}$ M Schoenbaum, RAND, Arlington, VA USA.mikels@rand.org.

\section{Design}

Cost effectiveness analysis from a societal perspective for a cluster randomised \{allocation concealed*\} $\dagger$, unblinded,* controlled trial with 2 years of follow up.

\section{Setting}

46 primary care clinics in 6 community based managed care organisations (MCOs) in the USA.

\section{Patients}

1356 patients who were $\geqslant 18$ years of age mean age $44 \mathrm{y}, 71 \%$ women $\}$, planned to use the primary care clinic over the next 12 months, and met the Composite International Diagnostic Interview criteria for depression. Follow up at 2 years was $85 \%$.

\section{Intervention}

Matched clinics were allocated to 1 of 2 QI interventions or to usual care (ie, mailing of practice guidelines) (16 clinics, 443 patients). The QI interventions consisted of training for practice leaders and nurses, enhanced educational and assessment resources, and either nurses for medication follow up (QI-meds, 12 clinics, 424 patients) or access to trained psychotherapists (QI-treatment, 15 clinics, 489 patients).

\section{Main cost and outcome measures}

Outcomes were quality adjusted life years (QALYs), days with depression burden, and days of employment. Intervention costs (screening, intervention materials, and professional time) and healthcare costs (consultations and psychotropic medications) were assessed in 1998 US dollars. Indirect costs for patient time were included.

\section{Main results}

Intention to treat analyses were adjusted for baseline patient characteristics and practice randomisation blocks. Patients in the QI-treatment group had more QALYs $(\mathrm{p}=0.006)$, fewer days of depression burden $(\mathrm{p}=0.01)$, and more days of employment $(\mathrm{p}=0.03)$ than did those receiving usual care (table). QI-meds and usual care did not differ for any outcome (table). The groups did not differ for healthcare costs (including patient time) (table).

\section{Conclusion}

1 of 2 quality improvement interventions for depression in managed care was more effective but cost more than usual care.

*See glossary.

$\dagger$ Information provided by author.

† Wells KB, Sherbourne C, Schoenbaum M, et al.JAMA 2000;283:212-20.
2 quality improvement (QI) interventions v usual care for depression in primary care§

\begin{tabular}{|c|c|c|c|}
\hline Outcomes at 2 years & $\begin{array}{l}\text { Usual care } \\
\text { total }\end{array}$ & $\begin{array}{l}\text { Incremental effect of } \\
\text { Ql-meds }(95 \% \mathrm{Cl})\end{array}$ & $\begin{array}{l}\text { Incremental effect of } \\
\text { Ql-treatment (CI) }\end{array}$ \\
\hline $\begin{array}{l}\text { Quality adjusted life } \\
\text { years }\end{array}$ & 1.7 & $0.01(-0.00$ to 0.03$)$ & $0.02(0.01$ to 0.04$)$ ? \\
\hline $\begin{array}{l}\text { Days of depression } \\
\text { burden }\end{array}$ & 419.9 & $-25.0(-63.1$ to 13.2$)$ & $-46.7(-83.1$ to -10.3$)$ \\
\hline Days of employment & 279.2 & $17.9(-1.6$ to 37.4$)$ & 20.9 (2.4 to 39.3$)$ ๆ \\
\hline Healthcare costs $^{\star \star}$ (US $\$$ ) & 3835 & 419 ( -467 to 1306$)$ & $485(-393$ to 1363$)$ \\
\hline
\end{tabular}

\section{COMMENTARY}

The study by Schoenbaum et al joins many studies showing that standardised interventions improve depressed patients' perceptions of wellbeing but are not cost effective. ${ }^{12}$

The outcome measures in cost effectiveness studies of depression treatment are inherently subjective. Schoenbaum et al measured days of employment, modified QALYs, and depression burden as outcomes. The long study period and the clinical setting are other defining characteristics of this study.

Implicit in the study is that an academically rigorous QI programme can effectively improve the quality of depression care in an MCO setting; however, this improvement comes at a cost: the participating MCOs paid US $\$ 454$ (CI $-\$ 305$ to $\$ 1214$ ) more over 2 years for the intervention group than for the usual care group. The positive "lean" of the CI suggests that these interventions truly cost more than usual care. The range of cost per QALY was US $\$ 15331$ to $\$ 30663$ for QI-meds and US $\$ 9478$ to $\$ 18953$ for QI-treatment.

If the intervention cost per QALY can be kept under US $\$ 50000$, the cost for depression treatment is similar to that for high blood pressure. ${ }^{3}$ As depression is the fourth leading cause of disease burden worldwide, ${ }^{4}$ treatments proved to be effective and efficient can relieve suffering. But who is going to pay? Both patients and their employers can benefit from more stable employment status. Within MCOs, QI funding might be used.

The issue of financing needs further study. Furthermore, because concern exists that cost effectiveness findings are sensitive to the utility measure used, ${ }^{5}$ research on the measure that reflects the value of mental health to the individual, employers, and society as a whole is needed.

Margretta Diemer, MD, MPH

Christos Hatzigeorgiou, DO Walter Reed Army Medical Center, Washington, DC, USA

1 Simon GE, Katon WJ, VonKorff M, et al. Cost-effectiveness of a collaborative care program for primary care patients with persistent depression. Am J Psychiatry 2001;158:1638-44.

2 Von Korff M, Katon W, Bush T, et al. Treatment costs, cost offset, and cost-effectiveness of collaborative management of depression. Psychosom Med 1998;60:143-9.

3 Stone PW, Teutsch S, Chapman RH, et al. Cost-utility analyses of clinical preventive services: published ratios, 1976-1997. Am J Prev Med 2000;19:15-23.

4 Murray CJ, Lopez AD. Global mortality, disability, and the contribution of risk factors: Global Burden of Disease Study. Lancet 1997;349:1436-42.

5 Donald Sherbourne C, Unützer J, Schoenbaum M, et al. Can utility-weighted health-related quality-of-life estimates capture health effects of quality improvement for depression? Med Care 2001;39:1246-59. 